\title{
Morphology, Dielectric and EMI Shielding Characteristics of Graphene Nanoplatelets, Montmorillonite Nanoclay and Titanium Dioxide Nanoparticles Reinforced Polyvinylidenefluoride Nanocomposites
}

\author{
A. Harish Kumar ${ }^{1} \cdot$ M. Basheer Ahamed ${ }^{1} \cdot$ Kalim Deshmukh $^{2} \cdot$ Mohamed Sheik Sirajuddeen $^{1}$
}

Received: 26 October 2020 / Accepted: 20 December 2020 / Published online: 4 January 2021

(C) The Author(s), under exclusive licence to Springer Science+Business Media, LLC part of Springer Nature 2021

\begin{abstract}
Herein, flexible polyvinylidenefluoride (PVDF) nanocomposite films reinforced with different concentrations of graphene nanoplatelets (GNPs), montmorillonite (MMT) nanoclay and titanium dioxide $\left(\mathrm{TiO}_{2}\right)$ nanoparticles $(\mathrm{NPs})$ were prepared using a simple and low-cost solution casting method. The surface morphology of PVDF/GNPs/TiO $/ \mathrm{MMT}_{2}$ nanocomposites and the interaction between PVDF, GNPs, $\mathrm{TiO}_{2}$ NPs and MMT nanofillers was examined using Fourier transform infrared (FTIR) spectroscopy, X-ray diffraction (XRD) and field emission scanning electron microscopy (FESEM) techniques. The dielectric properties of the prepared nanocomposite films were evaluated using a frequency response impedance analyzer in the frequency range from $50 \mathrm{~Hz}$ to $20 \mathrm{MHz}$ at various temperatures. The electromagnetic interference (EMI) shielding effectiveness (SE) of PVDF/GNPs/ $/ \mathrm{TiO}_{2} / \mathrm{MMT}$ nanocomposites was measured in the Ku-band region (12-18 GHz) and the maximum SE of $12.6 \mathrm{~dB}$ was obtained for nanocomposites with GNPs-2.5\%, MMT-1\% and $\mathrm{TiO}_{2}-11.5 \%$. Considering the excellent EMI shielding performance, these nanocomposites can have promising applications in smart electronics and flexible devices.
\end{abstract}

Keywords $\mathrm{PVDF} \cdot \mathrm{GNPs} \cdot \mathrm{TiO}_{2} \mathrm{NPs} \cdot \mathrm{MMT} \cdot \mathrm{EMI}$ shielding $\cdot \mathrm{SEM}$

\section{Introduction}

The boundless and explosive growth in the electrical, electronics and telecommunication industries have enabled the substantial generation of unwanted electromagnetic (EM) pollution which is known as electromagnetic interference, EMI [1,2]. The EM radiation emitted from the source generates considerable heat emissions thereby affecting the normal operation of electronic equipment and also leads to the malfunctioning of the neighbouring instruments $[3,4]$. The EM radiations are also hazardous and can have serious effects on human health. Therefore, EMI shielding materials are essential to shield or to reduce the effect of this

M. Basheer Ahamed

basheerahamed@crescent.education

1 Department of Physics, B. S. Abdur Rahman Crescent Institute of Science and Technology, Vandalur, Chennai 600048, India

2 New Technologies-Research Centre, University of West Bohemia, 30100 Plzeň, Czech Republic undesired pollution $[5,6]$. The shielding material must have high absorption, high reflection and very less or negligible transmittance of EM radiation [3-8]. Traditionally, metals have been frequently used for EMI shielding because of their excellent conductivity, but they exhibit several drawbacks such as poor processability, high density, narrow absorption bandwidth, corrosive nature and heavyweight, etc. [5-9]. Therefore, nowadays, researchers are gradually replacing metal-based materials with flexible and low-cost polymer nanocomposites (PNCs) for the development of novel and efficient EMI shielding materials.

Recently, PNCs have attracted great attraction in different research fields because of their lightweight, easy processability, flexibility, low cost and excellent properties which can be tailored as per specific application needs [10-15]. Based on the intended applications, different types of conducting nanoparticles (NPs), metal oxides, metal and fibers or clay nanopowders can be added to a polymer matrix to achieve effective and homogeneous dispersion within the polymer matrix to obtain significant enhancement in the desired properties [16-20]. Furthermore, studies have shown that integrating two or more fillers into the polymer matrix 
can be more resourceful in achieving enhanced EMI SE [21-24]. Polyvinylidene fluoride (PVDF) is one of the most frequently investigated polymers especially used for preparing flexible PNCs. It is a semi-crystalline, ferroelectric polymer with good thermal stability, high melting point, excellent mechanical and dielectric properties [25, 26]. PVDF has mainly four crystal polymorphic phases namely $\alpha, \beta, \gamma$ and $\delta$. Among them, the $\alpha$-phase is the most common and stable polymorph [25-27]. The phase behaviour of PVDF has been studied extensively where the $\beta$-phase of PVDF was found to have good functionality, high tensile toughness, excellent piezoelectric and pyroelectric properties and good processability [28-30]. Thus, PVDF is a very promising polymeric material in the field of EMI shielding nanocomposites.

Graphene is an outstanding two-dimensional (2D) material comprising $\mathrm{sp}^{2}$ bonded carbon atoms arranged in a honeycomb structure [31]. Graphene exhibits excellent optical, electrical, thermal and tensile properties [31, 32]. These intriguing properties of graphene have triggered enormous interest in its implementation in a vast number of applications such as supercapacitors [33], fuel cells [34], photonics and optoelectronics [35] and lithium-ion batteries [36]. Graphene nanoplatelets (GNPs) are composed of single or few-layer graphene with thicker graphite [37]. GNPs exhibit a planar structure with excellent properties such as large aspect ratio, lightweight, excellent electrical and thermal conductivity and mechanical strength [37, 38]. Furthermore, GNPs based PNCs have demonstrated improved flexural and tribological properties [39, 40]. Montmorillonite (MMT) consists of an intercalated structure with an expanded interlayer spacing of layered aluminosilicates [41]. MMT nanoclay particles are frequently used as filler materials that can be efficiently dispersed within the polymer matrix. Studies have revealed enhanced structural and tribological properties of PNCs when MMT was dispersed into the PVDF matrix $[42,43]$. Titanium dioxide $\left(\mathrm{TiO}_{2}\right) \mathrm{NPs}$ have been the most widely used nanofiller in the development of PNCs owing to their promising properties such as good chemical stability, high refractive index, good dielectric properties and excellent corrosion resistance [44, 45]. $\mathrm{TiO}_{2} \mathrm{NPs}$ reinforced PNCs have been shown to display considerable antibacterial activity, mechanical, dielectric and flame retardant properties [46-48].

The EMI shielding properties of various PNCs or hybrid materials have been investigated by several authors owing to their superior electrical properties. For example; Sabira et al. [49] developed $20 \mu \mathrm{m}$ thick, flexible, and mechanically stable PVDF/graphene nanocomposite films and observed an EMI SE value of $47 \mathrm{~dB}$ in the X-band frequency region. Hamidinejad et al. [50] fabricated high-density polyethylene/GNPs composite foams by supercritical fluid treatment and physical foaming process. The resultant composite foam exhibited an EMI SE of $31.6 \mathrm{~dB}$ at 19 vol\% GNPs loading.
In another study, Vyas and Chandra [23] reported poly (vinylidene fluoride-co-hexafluoropropylene) (PVDF-HFP) nanocomposite films comprising multi-walled carbon nanotubes (MWCNTs) as an electron-conducting network and barium titanate $\left(\mathrm{BaTiO}_{3}\right)$ as ferroelectric ceramic nanofiller. The resultant composite exhibited EMI SE value of $\sim 81 \mathrm{~dB}$ in the X-band ( $8-12 \mathrm{GHz})$ region. These studies demonstrate that several factors such as size, shape, structure, thickness, filler content, conductivity and percolation threshold are responsible for achieving enhanced EMI SE of PNCs $[38,49-51]$. Also, increasing the nanofiller content into the polymer matrix leads to an improved conductivity and low leakage current of the nanocomposites thereby providing enhanced EMI SE values [23]. Thus, with this background knowledge, in the present work, GNPs, MMT and $\mathrm{TiO}_{2} \mathrm{NPs}$ reinforced PVDF nanocomposites were prepared and their dielectric and EMI shielding properties were examined.

\section{Experimental Procedure}

\subsection{Materials}

PVDF powder was purchased from Pragati Plastics PVT Ltd., New Delhi, India. GNPs (Type 1) of carbon content $99.5 \%$, thickness $6-8 \mathrm{~nm}$ and average particle size of $15 \mu \mathrm{m}$ and MMT nanopowder of average particle size $80-150 \mathrm{~nm}$ and elemental compositions $\mathrm{SiO}_{2}-65 \%, \mathrm{Al}_{2} \mathrm{O}_{3}-15 \%$, $\mathrm{Fe}_{2} \mathrm{O}_{3}-1.3 \%, \mathrm{Ti}_{2} \mathrm{O}-0.19 \%, \mathrm{~K}_{2} \mathrm{O}-1.3 \%, \mathrm{Na}_{2} \mathrm{O}-0.65 \%, \mathrm{CaO}-$ $3.31 \%$ and $\mathrm{MgO}-0.99 \%$ was purchased from Sisco Research Laboratories (SRL) Pvt. Ltd., Mumbai, India. $\mathrm{TiO}_{2} \mathrm{NPs}$ employed in this study was AEROXIDE hydrophilic fumed $\mathrm{TiO}_{2} \mathrm{P} 25$ with an average particle size of $21 \mathrm{~nm}$, high specific surface area of $50 \pm 15 \mathrm{~m}^{2} / \mathrm{g}$ and crystallographic composition of $80 \%$ anatase and $20 \%$ rutile was supplied by Degussa, Germany. $N, N$-dimethylformamide (DMF) with $>99 \%$ purity used as the solvent in the present study was supplied by Qualigens Fine Chemicals, Mumbai, India.

\subsection{Preparation of PVDF/GNPs/MMT/TiO Nanocomposite Films}

The PVDF/GNPs/MMT/TiO 2 nanocomposite films were prepared using the solution casting method as illustrated in Fig. 1. The feed compositions used for the preparation of nanocomposite films are shown in Table 1. Initially, the desired amount of PVDF powder was dissolved in $20 \mathrm{ml}$ DMF by heating at $70{ }^{\circ} \mathrm{C}$ in the hot air oven until a clear solution was obtained. Meanwhile, GNPs were dispersed in $15 \mathrm{ml} \mathrm{DMF}$ and sonicated using an ultrasonic bath (Model: LMUC-2, capacity 21 , ultrasonic frequency $40 \mathrm{kHz}$, heating ambient to $80{ }^{\circ} \mathrm{C}$, timer 0 to $60 \mathrm{~min}$, power supply $220 \mathrm{~V}, 50 \mathrm{~Hz}$ ) for $1 \mathrm{~h}$. Similarly, the $\mathrm{TiO}_{2}$ NPs and MMT 


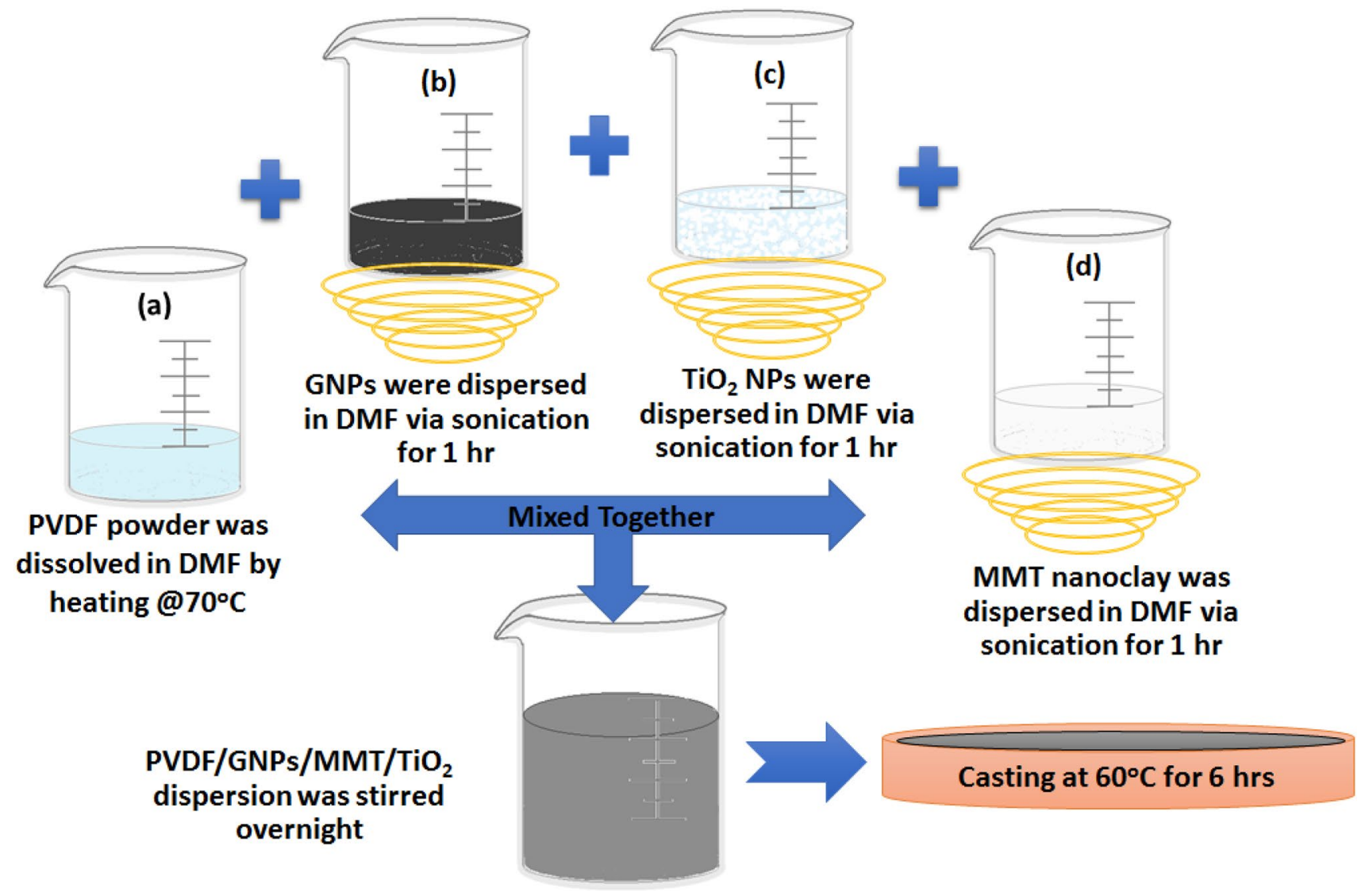

Fig. 1 Schematic representation of synthesis procedure

Table 1 Feed compositions of $\mathrm{PVDF} / \mathrm{GNPs} / \mathrm{MMT} / \mathrm{TiO}_{2}$ nanocomposite films

\begin{tabular}{llll}
\hline PVDF (wt\%) & GNPs (wt\%) & MMT (wt\%) & $\mathrm{TiO}_{2}(\mathrm{wt} \%)$ \\
\hline 100 & 0 & 0 & 0 \\
85 & 0.5 & 5 & 9.5 \\
85 & 1 & 4 & 10 \\
85 & 1.5 & 3 & 10.5 \\
85 & 2 & 2 & 11 \\
85 & 2.5 & 1 & 11.5 \\
85 & 3 & 0 & 12 \\
\hline
\end{tabular}

nanopowder was dispersed separately in $15 \mathrm{ml}$ DMF by ultrasonication. The sonicated GNPs dispersion was then added to the PVDF solution followed by continuous stirring for $3 \mathrm{~h}$. Likewise, the sonicated $\mathrm{TiO}_{2}$ NPs and MMT nanoclay dispersions were respectively added to the PVDF/ GNPs mixture. Later, the resulting PVDF/GNPs/MMT/ $\mathrm{TiO}_{2}$ mixture was stirred vigorously overnight at room temperature to obtain a homogeneous dispersion of nanofillers into the polymer matrix. Finally, the homogeneous PVDF/ GNPs/MMT/TiO 2 dispersion was poured onto the Teflon
Petri dish and dried at $60{ }^{\circ} \mathrm{C}$ for $6 \mathrm{~h}$ to obtain PVDF/GNPs/ $\mathrm{MMT} / \mathrm{TiO}_{2}$ nanocomposite films that were used for further characterizations.

\subsection{Characterization Details}

The FTIR spectra of pristine PVDF and PVDF/GNPs/ $\mathrm{MMT} / \mathrm{TiO}_{2}$ nanocomposite films were obtained using Fourier transform infrared spectrophotometer (Shimadzu, IR Tracer-100, Japan) in the transmission mode within 400 to $4000 \mathrm{~cm}^{-1}$ wavenumber range.

The XRD patterns of pristine PVDF, GNPs, MMT, $\mathrm{TiO}_{2}$ NPs and PVDF/GNPs/MMT/TiO 2 nanocomposite films were taken using the X-ray source (Philips XPert MPD diffractometer, Eindhoven, The Netherlands) with $\mathrm{Cu} \mathrm{K} \alpha$ radiation of wavelength $\lambda=1.5406 \AA$ in the $2 \theta$ range from 10 to $80^{\circ}$ with $1^{\circ} / \mathrm{min}$ scanning speed and $0.01^{\circ}$ step size.

The surface morphology of PVDF/GNPs/MMT/TiO nanocomposite films was evaluated using the field emission scanning electron microscope (FESEM; Tescan, MIRA3, Czech Republic) at different magnifications with an applied accelerating voltage of $20 \mathrm{kV}$. 
Dielectric properties of the prepared PVDF/GNPs/MMT/ $\mathrm{TiO}_{2}$ nanocomposite films were studied using a frequency response impedance analyzer (N4L PSM 1735 NumetriQ, UK). The nanocomposite films were examined as a function of frequency ranging from $50 \mathrm{~Hz}$ to $20 \mathrm{MHz}$ at different temperatures.

The EMI SE properties of PVDF and PVDF/GNPs/ $\mathrm{MMT} / \mathrm{TiO}_{2}$ nanocomposite films were measured by using an $8510 \mathrm{C}$ vector network analyzer (VNA), Agilent Technologies, USA, in Ku-band (12-18 GHz) frequency region.

\section{Results and Discussion}

\subsection{FTIR Spectroscopy}

Figure 2 shows the FTIR transmittance spectra of pristine PVDF, PVDF/GNPs/MMT/TiO 2 and PVDF/GNPs/TiO 2 nanocomposite films for different content of GNPs, MMT and $\mathrm{TiO}_{2} \mathrm{NPs}$ into the PVDF matrix. In the FTIR spectrum of pristine PVDF (Fig. 2a), the small peaks at $3014 \mathrm{~cm}^{-1}$ and $2978 \mathrm{~cm}^{-1}$ are attributed to symmetric and asymmetric stretching vibrations of $-\mathrm{CH}_{2}$ group respectively [29]. The peak at $1400 \mathrm{~cm}^{-1}$ can be assigned to $-\mathrm{CH}_{2}$ bending vibrations while the peaks at 1067,1160 and $1400 \mathrm{~cm}^{-1}$ show the presence of the $\alpha-\mathrm{PVDF}$ phase [46]. The peak at $893 \mathrm{~cm}^{-1}$ can be assigned to $\mathrm{CH}_{2}$ rocking and $\mathrm{CF}_{2}$ asymmetric stretching vibrations. Moreover, the peaks at 822 , 893 and $1331 \mathrm{~cm}^{-1}$ show the presence of the $\beta$-PVDF phase $[52,53]$. The peaks around $621 \mathrm{~cm}^{-1}$ can be assigned to $-\mathrm{CF}_{2}$ bending while the peak at $490 \mathrm{~cm}^{-1}$ can be attributed to $-\mathrm{CF}_{2}$ bending and wagging vibrations [53]. The FTIR spectra of PVDF/GNPs/MMT/TiO ${ }_{2}$ nanocomposites (Fig. 2b-g) show new peaks due to the incorporation of GNPs, MMT and $\mathrm{TiO}_{2}$ NPs into the PVDF matrix. The peaks appearing at $1055 \mathrm{~cm}^{-1}$ can be assigned to stretching vibrations of the $\mathrm{Si}-\mathrm{O}$ group while the peaks at $540 \mathrm{~cm}^{-1}$ and $473 \mathrm{~cm}^{-1}$ are attributed to $\mathrm{Al}-\mathrm{O}$ and $\mathrm{Si}-\mathrm{O}-\mathrm{Si}$ bending vibrations respectively. Also, the peak at $625 \mathrm{~cm}^{-1}$ can be assigned for $\mathrm{Al}-\mathrm{O}$ and $\mathrm{Si}-\mathrm{O}$ out of plane vibrations of MMT [54]. The peaks for GNPs at 1067 and $1160 \mathrm{~cm}^{-1}$ are merged with peaks of PVDF and the peak corresponding
Fig. 2 FTIR spectra of PVDF, $\mathrm{PVDF} / \mathrm{GNP} / \mathrm{MMT} / \mathrm{TiO}_{2}$ and $\mathrm{PVDF} / \mathrm{GNPs} / \mathrm{TiO}_{2}$ nanocomposite films (a) PVDF, (b) PVDF/GNPs/MMT/TiO nanocomposite film with GNPs$0.5 \%$, MMT- $5 \%$ and $\mathrm{TiO}_{2}-9.5 \%$, (c) GNPs- $1 \%$, MMT- $4 \%$ and $\mathrm{TiO}_{2}-10 \%$, (d) GNPs- $1.5 \%$, MMT-3\% and $\mathrm{TiO}_{2}-10.5 \%$, (e) GNPs-2\%, MMT-2\% and $\mathrm{TiO}_{2}-11 \%$, (f) GNPs- $2.5 \%$, MMT- $1 \%$ and $\mathrm{TiO}_{2}-11.5 \%$ and (g) GNPs-3\% and $\mathrm{TiO}_{2}-12 \%$

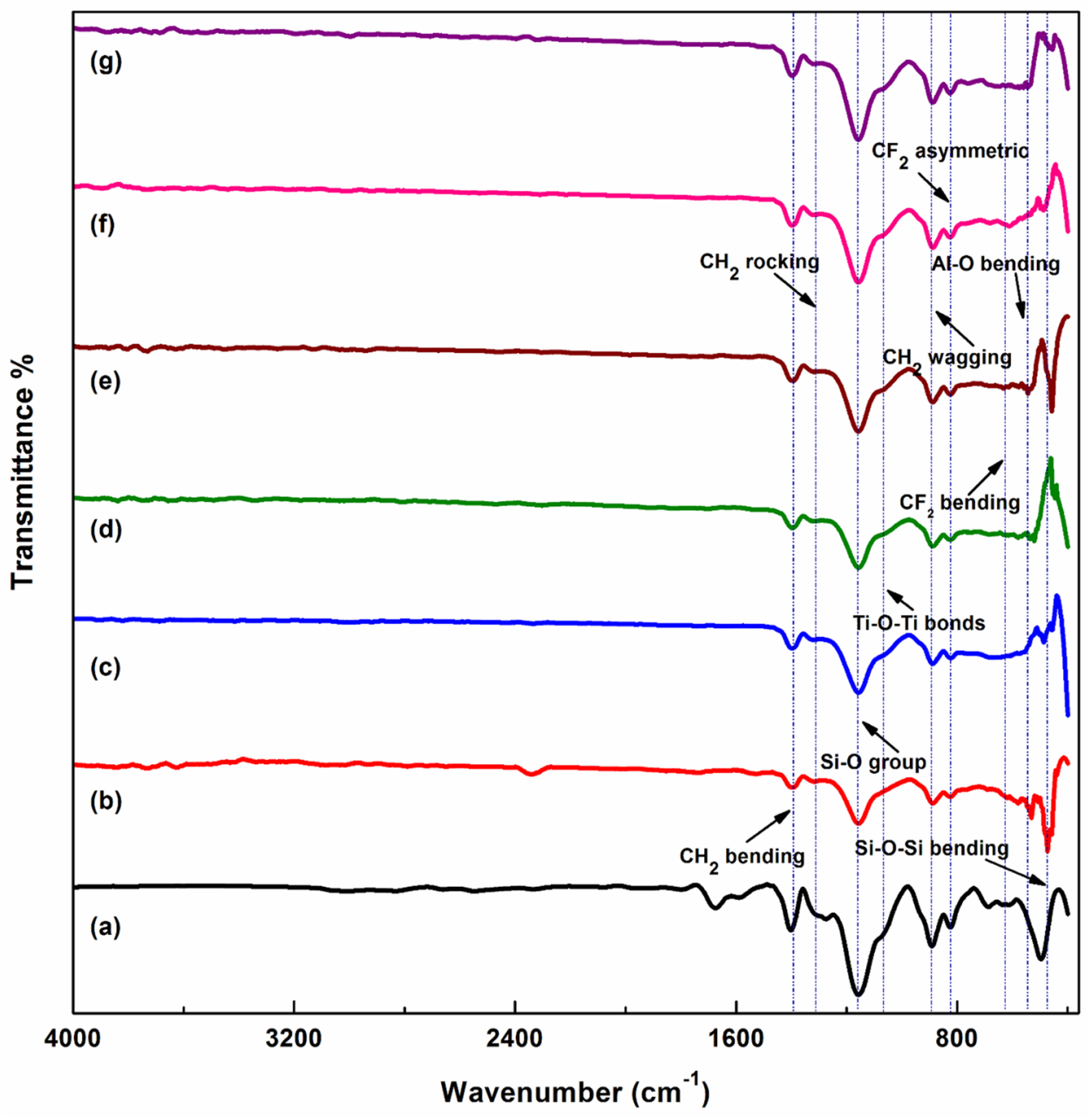


to the stretching vibrations of $\mathrm{Ti}-\mathrm{O}-\mathrm{Ti}$ bonds of $\mathrm{TiO}_{2} \mathrm{NPs}$ appears at $462 \mathrm{~cm}^{-1}$ [46]. Therefore, the FTIR spectra of $\mathrm{PVDF} / \mathrm{GNP} / \mathrm{MMT} / \mathrm{TiO}_{2}$ nanocomposites confirm the good interaction of nanofillers and the PVDF matrix.

\subsection{XRD Analysis}

The XRD patterns of pristine PVDF, $\mathrm{TiO}_{2}$ NPs, GNPs and MMT nanoclay are shown in Fig. 3. The pristine PVDF showed a characteristic diffraction peak at $2 \theta=20.05^{\circ}$ which is attributed to the (110) crystal plane of $\alpha$-phase while the second peak at $2 \theta=44.65^{\circ}$ is attributed to the (200) crystal plane of $\beta$-phase [21]. Besides, the diffraction pattern of PVDF also showed another prominent peak at $2 \theta=64.95^{\circ}$ which can be attributed to the (220) crystal plane [21]. The diffraction pattern of $\mathrm{TiO}_{2} \mathrm{NPs}$ showed several prominent XRD peaks at $2 \theta=25.24^{\circ}(101), 2 \theta=27.58^{\circ}$ (110), $2 \theta=37.98^{\circ}(004), 2 \theta=48.22^{\circ}(200), 2 \theta=53.98^{\circ}$ (105), $2 \theta=55.22^{\circ}(211), 2 \theta=62.76^{\circ}(204), 2 \theta=68.98^{\circ}$ (116), $2 \theta=70.36^{\circ}(220)$ and $2 \theta=75.28^{\circ}$ (215) which are

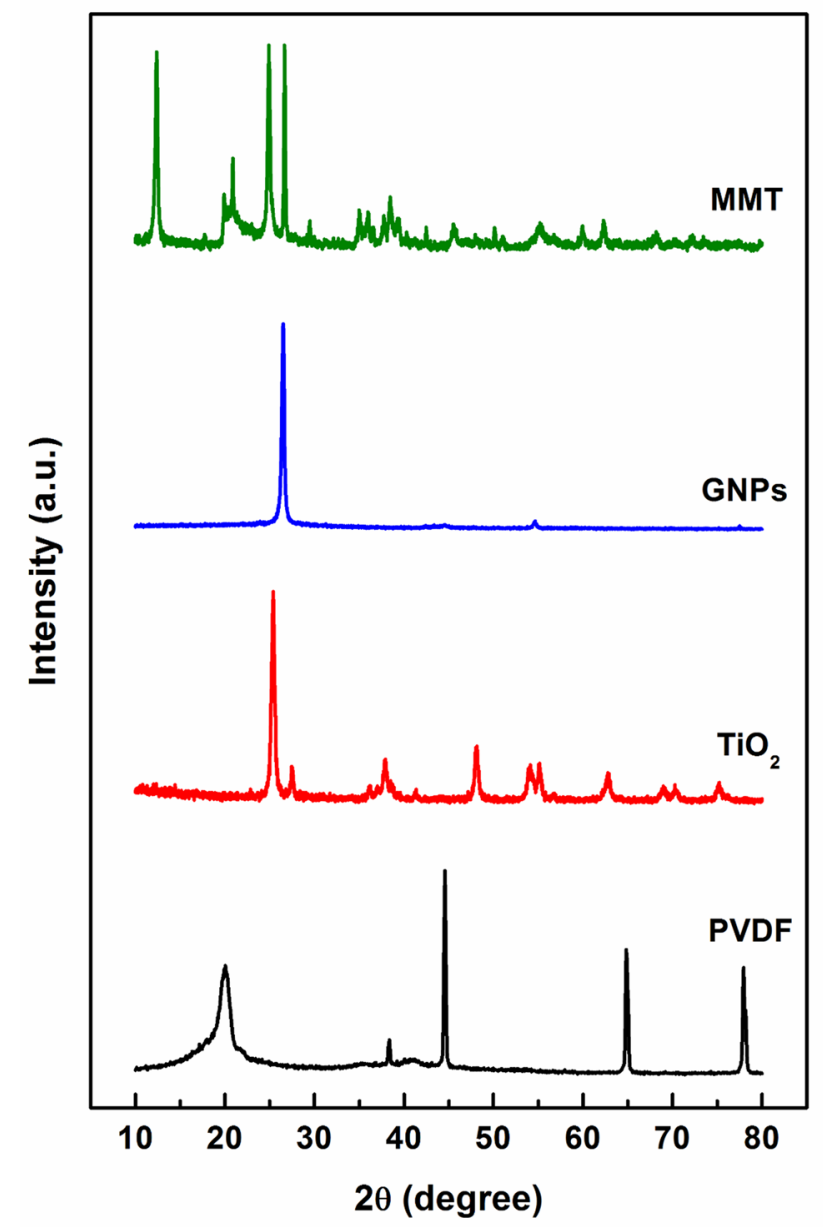

Fig. 3 XRD patterns of pristine PVDF, $\mathrm{TiO}_{2}$ NPs, GNPs and MMT nanoclay attributed to $80 \%$ anatase and $20 \%$ rutile crystallographic compositions [16]. The XRD pattern of GNPs showed a sharp and intense diffraction peak at $2 \theta=26.44^{\circ}$ and a small peak at $2 \theta=54.52^{\circ}$ demonstrating the highly crystalline graphite-like structure $[55,56]$. The XRD pattern of MMT nanoclay also displayed several prominent diffraction peaks associated with its lamellar structure. The diffraction peak at $2 \theta=12.52^{\circ}$ is attributed to (001) reflection while the peaks at $2 \theta=20.62^{\circ}(100)$ and $2 \theta=35.08^{\circ}$ (110) are associated with pyrophyllite mineral phase of MMT $[57,58]$. The XRD patterns of PVDF/GNPs/MMT/TiO 2 and PVDF/ GNPs/ $/ \mathrm{TiO}_{2}$ nanocomposite films are depicted in Fig. 4. All the characteristics diffraction peaks of the polymer matrix and the nanofillers were observed in the XRD patterns of the nanocomposite films. However, the intensity of these XRD peaks in nanocomposites was lower as compared with the intensity of the XRD peaks of pristine components. This suggests good compatibility and strong interaction between the polymer matrix and the nanofillers that resulted in the formation of homogeneous nanocomposites.

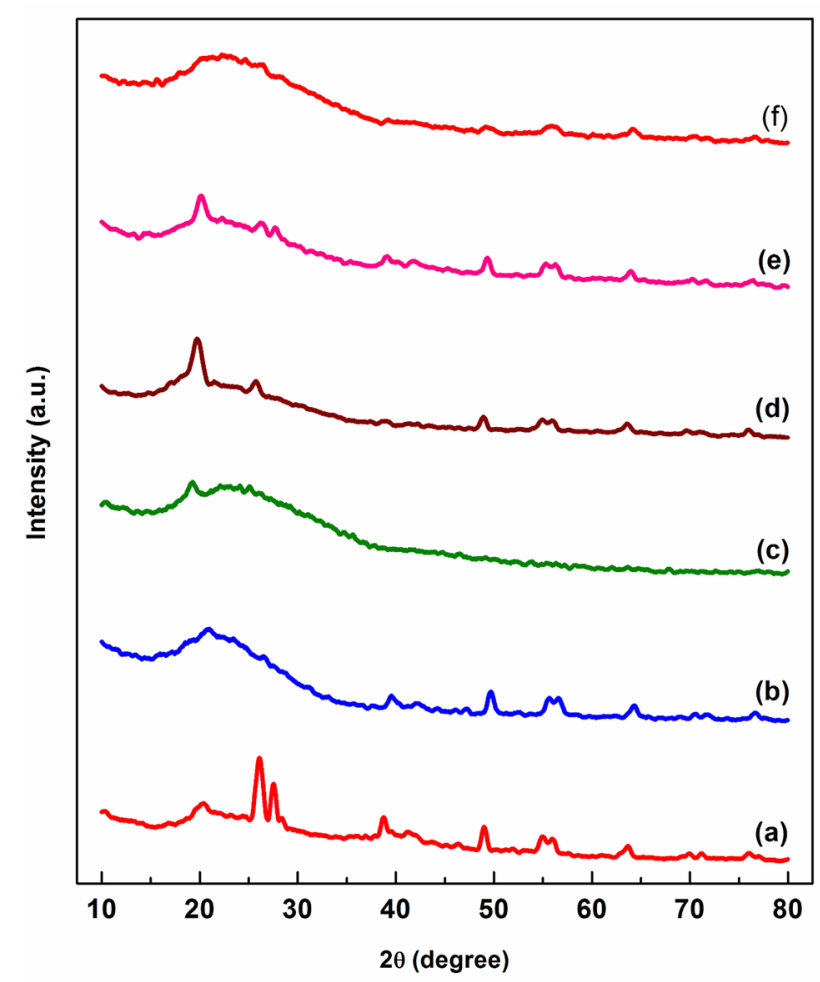

Fig. 4 XRD patterns of $\mathrm{PVDF} / \mathrm{GNP} / \mathrm{MMT} / \mathrm{TiO}_{2}$ nanocomposite film with (a) GNPs- $0.5 \%$, MMT-5\% and $\mathrm{TiO}_{2}-9.5 \%$, (b) GNPs- $1 \%$, MMT- $4 \%$ and $\mathrm{TiO}_{2}-10 \%$, (c) GNPs- $1.5 \%$, MMT-3\% and $\mathrm{TiO}_{2}-10.5 \%$, (d) GNPs- $2 \%$, MMT-2\% and $\mathrm{TiO}_{2}-11 \%$, (e) GNPs- $2.5 \%$, MMT-1\% and $\mathrm{TiO}_{2}-11.5 \%$, and (f) $\mathrm{PVDF} / \mathrm{GNPs} / \mathrm{TiO}_{2}$ nanocomposite film with GNPs- $3 \%$ and $\mathrm{TiO}_{2}-12 \%$ 


\subsection{FESEM Analysis}

Figure 5a-f shows FESEM images of three varied compositions of PVDF/GNPs/MMT/TiO ${ }_{2}$ nanocomposite films at different magnifications which revealed that the nanofillers i.e. GNPs, MMT and $\mathrm{TiO}_{2}$ NPs are homogeneously dispersed within the PVDF matrix. The FESEM image of PVDF/GNPs/MMT/TiO ${ }_{2}$ nanocomposite film
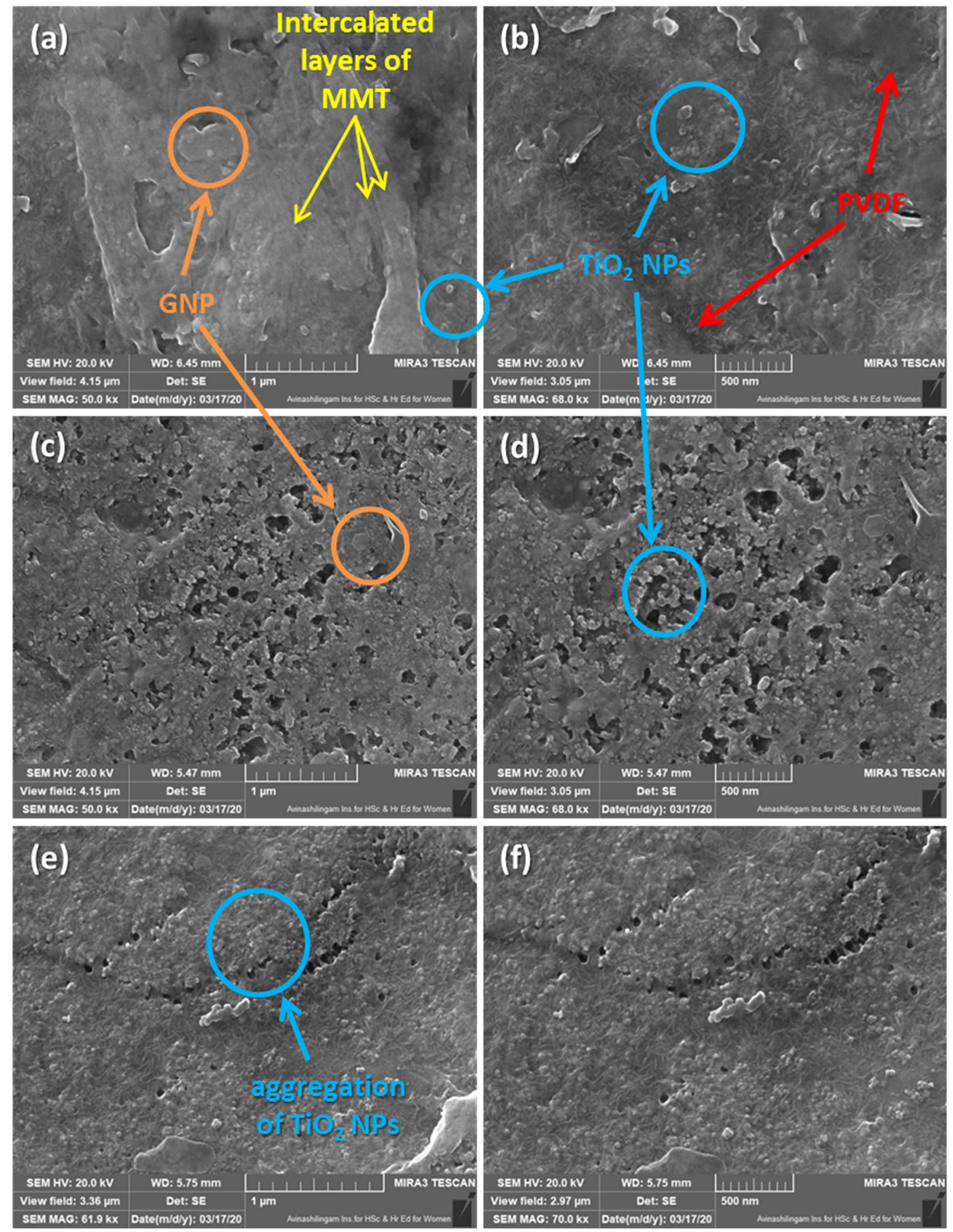

Fig. 5 a, b FESEM micrographs of PVDF/GNPs/MMT/TiO ${ }_{2}$ nanocomposite film with GNPs-1\%, MMT-4\% and $\mathrm{TiO}_{2}-10 \%$ at different magnifications, $\mathbf{c}, \mathbf{d}$ GNPs-2\%, MMT-2\% and $\mathrm{TiO}_{2}-11 \%$ at different magnifications and $\mathbf{e}, \mathbf{f}$ GNPs- $3 \%$ and $\mathrm{TiO}_{2}-12 \%$ at different magnifications 
with GNPs- $1 \%$, MMT-4\% and $\mathrm{TiO}_{2}-10 \%$ (Fig. 5a) shows randomly distributed intercalated layered stacks of MMT and also shows evenly distributed GNPs and $\mathrm{TiO}_{2}$ NPs. On higher loading of GNPs and $\mathrm{TiO}_{2}$ NPs with a decrease in MMT loading, the FESEM image of PVDF/GNPs/MMT/ $\mathrm{TiO}_{2}$ nanocomposite film with GNPs-2\%, MMT-2\% and $\mathrm{TiO}_{2}-11 \%$ (Fig. 5b) shows some aggregation of $\mathrm{TiO}_{2} \mathrm{NPs}$ with segregated GNPs. However, the little aggregation of $\mathrm{TiO}_{2}$ NPs with the intercalated layers of MMT enhances the properties of the nanocomposites. On further increasing the $\mathrm{TiO}_{2}$ NPs loading along with GNPs, the FESEM image of PVDF/GNPs/MMT/TiO ${ }_{2}$ nanocomposite film with GNPs-2\%, MMT-2\% and $\mathrm{TiO}_{2}-11 \%$ (Fig. 5c) showed big aggregates of $\mathrm{TiO}_{2}$ NPs. The FESEM micrographs of the nanocomposites demonstrates the uniform distribution of nanofillers throughout the PVDF matrix.
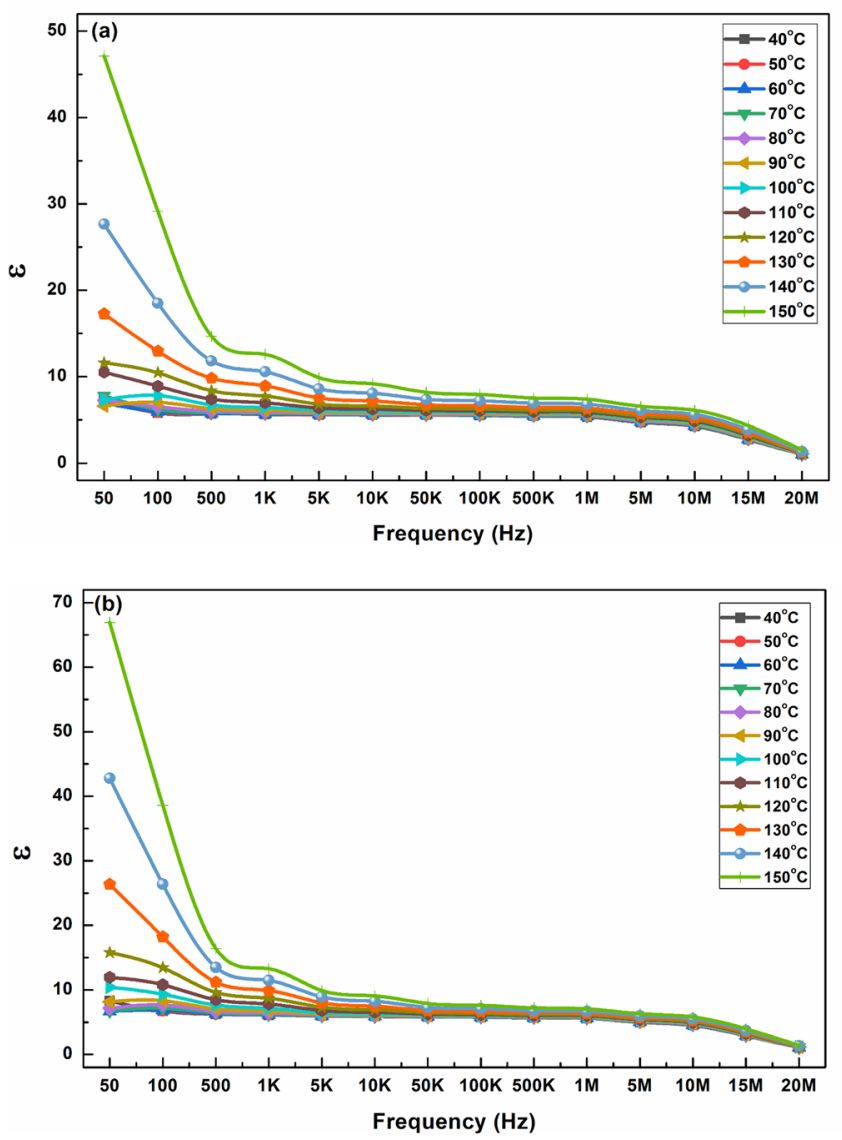

Fig. 6 a Dielectric constants for pristine PVDF film as a function of frequency at various temperatures. b Dielectric constants for PVDF/ GNPs/MMT/TiO 2 nanocomposite film with GNPs-0.5\%, MMT-5\% and $\mathrm{TiO}_{2}-9.5 \%$ as a function of frequency at various temperatures. c Dielectric constants for $\mathrm{PVDF} / \mathrm{GNPs} / \mathrm{MMT} / \mathrm{TiO}{ }_{2}$ nanocomposite film with GNPs- $1 \%$, MMT- $4 \%$ and $\mathrm{TiO}_{2}-10 \%$ as a function of frequency at various temperatures. d Dielectric constants for PVDF/ GNPs/MMT/TiO 2 nanocomposite film with GNPs-1.5\%, MMT-3\% and $\mathrm{TiO}_{2}-10.5 \%$ as a function of frequency at various temperatures.

\subsection{Dielectric Properties}

In the present study, the dielectric properties of the prepared nanocomposite films were investigated and the dielectric constant was determined using the relation [59];

$\varepsilon=\mathrm{C}_{\mathrm{p}} \mathrm{t} / \varepsilon_{0} \mathrm{~A}$,

where $C_{p}$ is capacitance, $t$ is thickness of the film, $\varepsilon_{0}$ is permittivity of free space, A is area of the film.

Figure 6a-g shows the variation in dielectric constants for pristine $\mathrm{PVDF}$ and $\mathrm{PVDF} / \mathrm{GNPs} / \mathrm{MMT} / \mathrm{TiO}_{2}$ nanocomposite films as a function of frequency for various temperatures. The maximum value of the dielectric constant observed for pristine PVDF film was 47.11 at $50 \mathrm{~Hz}$ and $150{ }^{\circ} \mathrm{C}$. On incorporating the nanofillers into the PVDF matrix, the
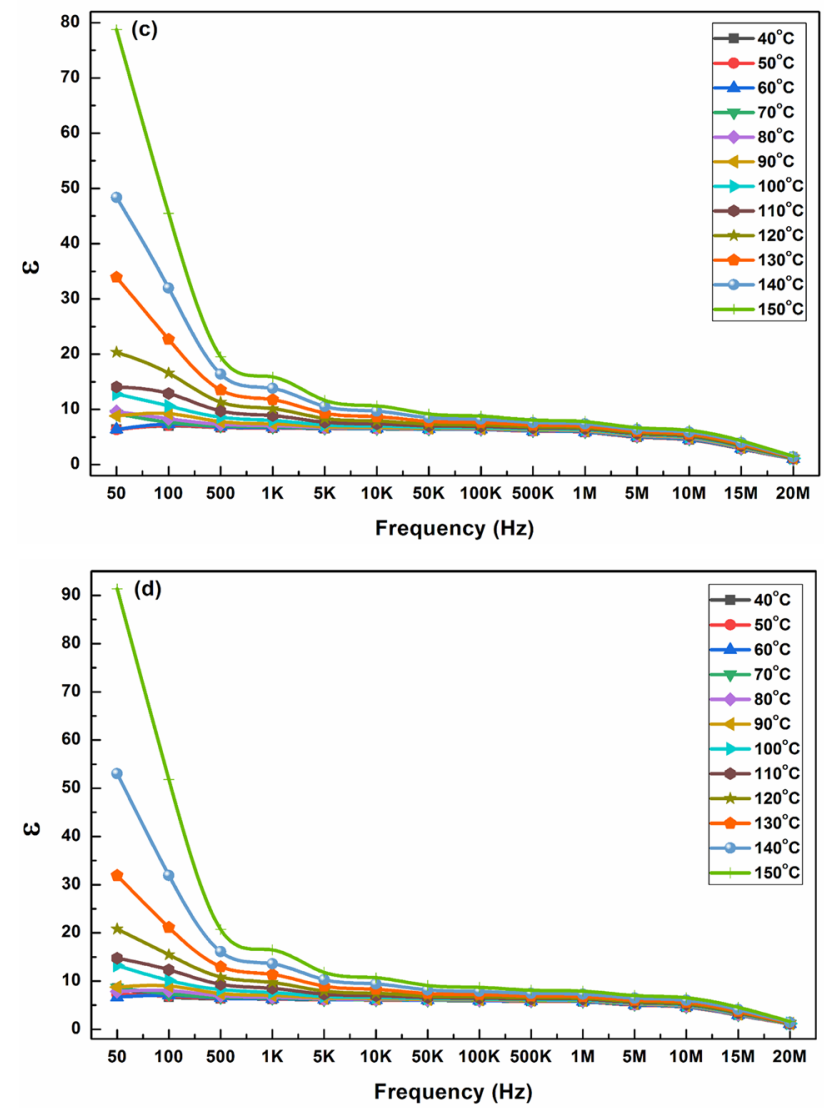

e Dielectric constants for PVDF/GNPs/MMT/TiO 2 nanocomposite film with GNPs-2\%, MMT-2\% and $\mathrm{TiO}_{2}-11 \%$ as a function of frequency at various temperatures. f Dielectric constants for PVDF/ GNPs/MMT/TiO 2 nanocomposite film with GNPs-2.5\%, MMT-1\% and $\mathrm{TiO}_{2}-11.5 \%$ as a function of frequency at various temperatures. g Dielectric constants for $\mathrm{PVDF} / \mathrm{GNPs} / \mathrm{TiO}_{2}$ nanocomposite film with GNPs-3\% and $\mathrm{TiO}_{2}-12 \%$ as a function of frequency at various temperatures 

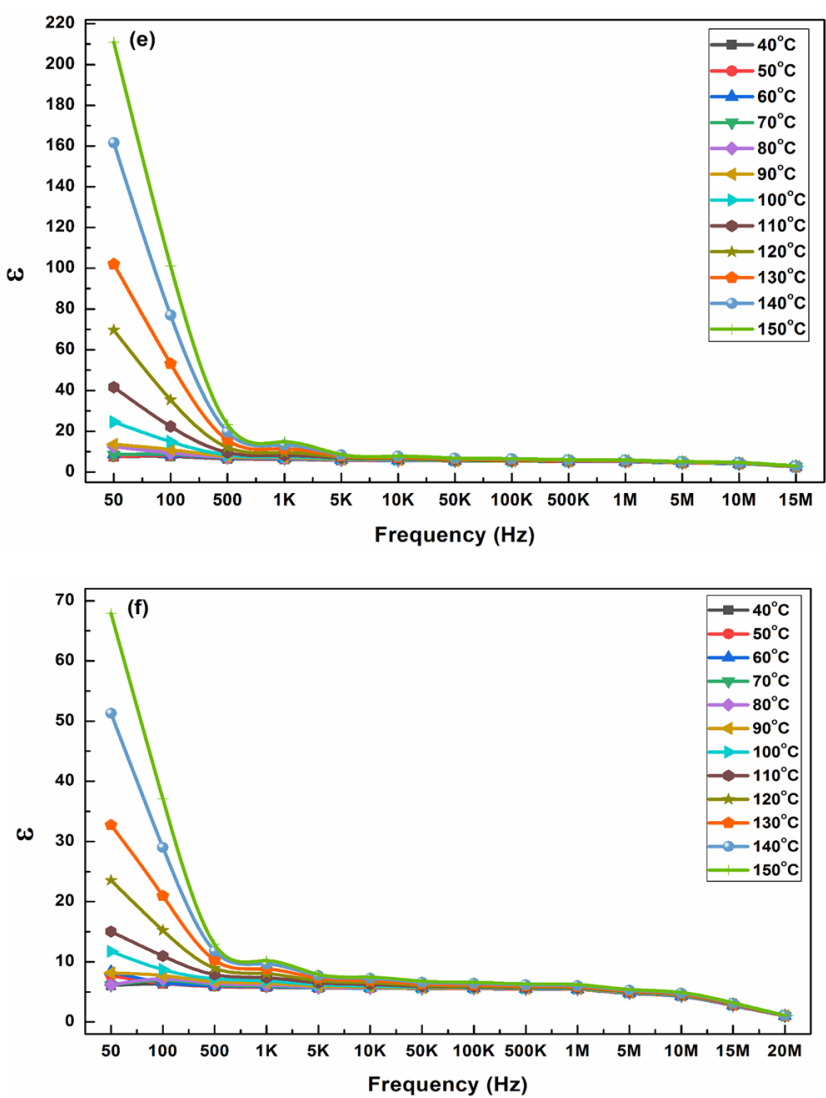

Fig. 6 (continued)

dielectric constant of the nanocomposites increased i.e. for $\mathrm{PVDF} / \mathrm{GNPs} / \mathrm{MMT} / \mathrm{TiO}_{2}$ nanocomposite film with GNPs$0.5 \%$, MMT-5\% and $\mathrm{TiO}_{2}-9.5 \%$, the maximum dielectric constant value was found to be 66.94 at $50 \mathrm{~Hz}$ and at $150{ }^{\circ} \mathrm{C}$. On higher loading of GNPs and $\mathrm{TiO}_{2}$ NPs with decreasing MMT loading, the dielectric constant of the nanocomposites reached the maximum value of 210.92 at $50 \mathrm{~Hz}$ and at $150{ }^{\circ} \mathrm{C}$ for $\mathrm{PVDF} / \mathrm{GNPs} / \mathrm{MMT} / \mathrm{TiO}_{2}$ nanocomposite film with GNPs-2\%, MMT-2\% and $\mathrm{TiO}_{2}-11 \%$. The high aspect ratio of GNPs and MMT effectively enhances the dielectric properties of the nanocomposites. Also, the fact that the addition of conducting fillers such as GNPs acts as electrodes and non-conducting counterparts as $\mathrm{MMT}$ and $\mathrm{TiO}_{2}$ NPs act as a dielectric medium, when they are embedded into the polymer matrix forming microcapacitors [46]. It can be observed that all the nanocomposite films exhibit high dielectric constant values at low frequencies. When the frequency was increased, the dielectric constant decrease to very low values. This can be attributed to the interfacial polarization or Maxwell-Wagner-Sillar (MWS) effect [60], i.e. the dielectric constants are higher at lower frequencies

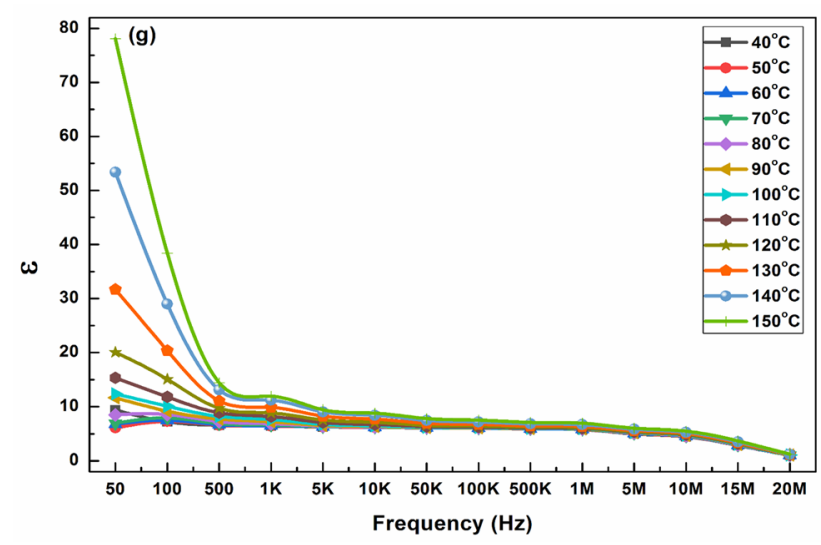

due to the induced and permanent dipoles which get aligned easily in this region. When the frequencies are higher, the dipoles have no time to get aligned, i.e., decreasing interfacial polarization or MWS effect [61]. On further increasing the concentration of GNPs and $\mathrm{TiO}_{2}$ NPs and decreasing MMT loading, the dielectric constant values decrease. This can be due to the agglomeration of $\mathrm{TiO}_{2} \mathrm{NPs}$ and further settling down on GNPs that deteriorate the dielectric properties of the nanocomposites.

Dielectric loss is another important parameter of dielectric materials that results from the inability of the polarization to follow the rate of change of applied electric field. In general, the distortional, dipolar, interfacial, and conduction loss in the dielectric materials constitutes the dielectric loss of the material [60]. Figure $7 \mathrm{a}-\mathrm{g}$ show the variations in the dielectric loss tangents for pristine PVDF and PVDF/ $\mathrm{GNPs} / \mathrm{MMT} / \mathrm{TiO}_{2}$ nanocomposite films as a function of frequency at various temperatures. The maximum value of dielectric loss tangent observed for pristine PVDF film was 5.4 at $50 \mathrm{~Hz}$ and $150^{\circ} \mathrm{C}$. For PVDF/GNPs/MMT/TiO ${ }_{2}$ nanocomposite film with GNPs-2\%, MMT-2\% and $\mathrm{TiO}_{2}-11 \%$, the maximum dielectric loss tangent value was found to be 

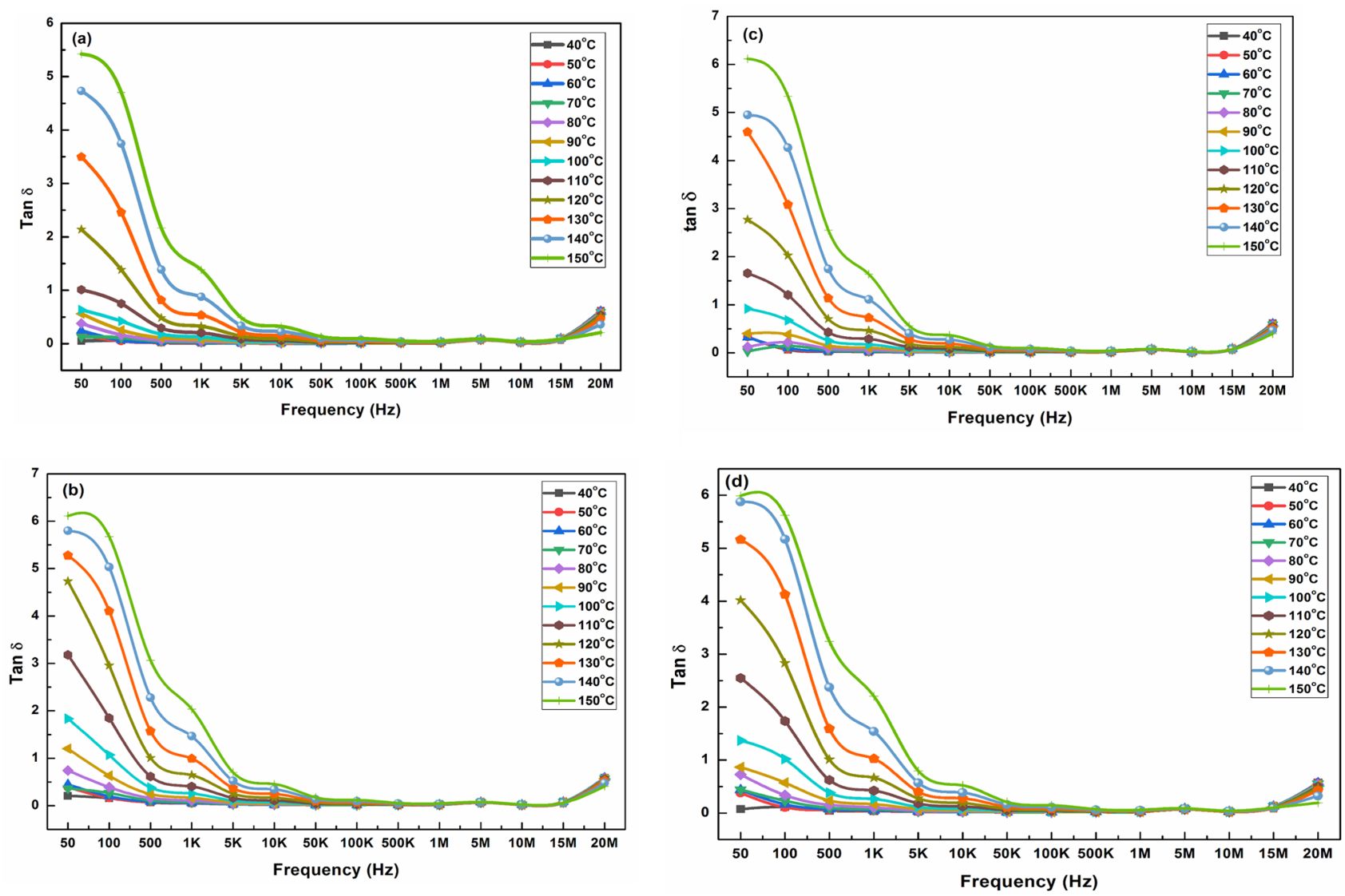

Fig. 7 a Dielectric loss tangents for pristine PVDF film as a function of frequency at various temperatures. b Dielectric loss tangents for PVDF/GNPs/MMT/TiO 2 nanocomposite film with GNPs- $0.5 \%$, MMT-5\% and $\mathrm{TiO}_{2}-9.5 \%$ as a function of frequency at various temperatures. c Dielectric loss tangents for PVDF/GNPs/MMT/TiO nanocomposite film with GNPs- $1 \%$, MMT- $4 \%$ and $\mathrm{TiO}_{2}-10 \%$ as a function of frequency at various temperatures. d Dielectric loss tangents for PVDF/GNPs/MMT/TiO 2 nanocomposite film with GNPs$1.5 \%$, MMT-3\% and $\mathrm{TiO}_{2}-10.5 \%$ as a function of frequency at vari-

ous temperatures. e Dielectric loss tangents for PVDF/GNPs/MMT/ $\mathrm{TiO}_{2}$ nanocomposite film with GNPs- $2 \%$, MMT- $2 \%$ and $\mathrm{TiO}_{2}-11 \%$ as a function of frequency at various temperatures. f Dielectric loss tangents for PVDF/GNPs/MMT/TiO 2 nanocomposite film with GNPs$2.5 \%$, MMT- $1 \%$ and $\mathrm{TiO}_{2}-11.5 \%$ as a function of frequency at various temperatures. g Dielectric loss tangents for $\mathrm{PVDF} / \mathrm{GNPs} / \mathrm{TiO}_{2}$ nanocomposite film with GNPs- $3 \%$ and $\mathrm{TiO}_{2}-12 \%$ as a function of frequency at various temperatures

10.4 at $50 \mathrm{~Hz}$ and $150{ }^{\circ} \mathrm{C}$. This indicates that the addition of conducting GNPs into the polymer increases the conductivity of the nanocomposites which leads to the leakage of charge current causing an increase in loss tangent values $[62,63]$. However, the dielectric constant values of all the nanocomposites are very much higher than their respective dielectric loss tangent values. This can be attributed to the good dispersion of nanofillers into the polymer matrix [60]. Table 2 gives the maximum dielectric constant and loss tangent values of the prepared nanocomposite films.

\subsection{EMI SE}

Figure 8 shows the EMI SE graph in the Ku band region for pristine $\mathrm{PVDF}$ and the $\mathrm{PVDF} / \mathrm{GNPs} / \mathrm{MMT} / \mathrm{TiO}_{2}$ nanocomposites. The pristine PVDF film shows EMI SE

of $\sim 5.39 \mathrm{~dB}$, which indicates its transparent shielding nature to EMI [4]. After the incorporation of nanofillers into the PVDF, the EMI SE raises to $\sim 10.3 \mathrm{~dB}$ for PVDF/ GNPs/MMT/TiO ${ }_{2}$ nanocomposite film with GNPs-0.5\%, MMT-5\% and $\mathrm{TiO}_{2}-9.5 \%$, then to $11.5 \mathrm{~dB}$ for PVDF/ GNPs/MMT/TiO 2 nanocomposite film with GNPs-2\%, MMT-2\% and $\mathrm{TiO}_{2}-11 \%$. The maximum value of EMI SE attained for the prepared nanocomposites was $\sim 12.6 \mathrm{~dB}$ for PVDF/GNPs/MMT/TiO ${ }_{2}$ nanocomposite film with GNPs- $2.5 \%$, MMT- $1 \%$ and $\mathrm{TiO}_{2}-11.5 \%$. This increase in EMI SE can be attributed to the increased conductivity of nanocomposites due to the incorporation of GNPs. This shows that the GNPs form interconnected layers of conducting network and high specific surface area is provided by MMT and $\mathrm{TiO}_{2}$ NPs. The effective enhancement in EMI SE can also be due to the attenuation in the scattering of 



Fig. 7 (continued)

Table 2 Maximum dielectric constant and dielectric loss tangent values for PVDF/GNPs/ $\mathrm{MMT} / \mathrm{TiO}_{2}$ nanocomposite films

\begin{tabular}{lll}
\hline Nanofiller loadings & Dielectric constant & Dielectric loss tangent \\
\hline Pristine PVDF & $47.11,50 \mathrm{~Hz}, 150{ }^{\circ} \mathrm{C}$ & $5.42,50 \mathrm{~Hz}, 150{ }^{\circ} \mathrm{C}$ \\
GNPs-0.5\%, MMT-5\% and $\mathrm{TiO}_{2}-9.5 \%$ & $66.94,50 \mathrm{~Hz}, 150{ }^{\circ} \mathrm{C}$ & $6.11,50 \mathrm{~Hz}, 150{ }^{\circ} \mathrm{C}$ \\
GNPs-1\%, MMT-4\% and $\mathrm{TiO}_{2}-10 \%$ & $78.74,50 \mathrm{~Hz}, 150{ }^{\circ} \mathrm{C}$ & $6.12,50 \mathrm{~Hz}, 150{ }^{\circ} \mathrm{C}$ \\
GNPs-1.5\%, MMT-3\% and $\mathrm{TiO}_{2}-10.5 \%$ & $91.36,50 \mathrm{~Hz}, 150{ }^{\circ} \mathrm{C}$ & $5.99,50 \mathrm{~Hz}, 150{ }^{\circ} \mathrm{C}$ \\
GNPs-2\%, MMT-2\% and $\mathrm{TiO}_{2}-11 \%$ & $210.92,50 \mathrm{~Hz}, 150{ }^{\circ} \mathrm{C}$ & $10.4,50 \mathrm{~Hz}, 150{ }^{\circ} \mathrm{C}$ \\
GNPs-2.5\%, MMT-1\% and $\mathrm{TiO}_{2}-11.5 \%$ & $67.88,50 \mathrm{~Hz}, 150{ }^{\circ} \mathrm{C}$ & $6.03,50 \mathrm{~Hz}, 150{ }^{\circ} \mathrm{C}$ \\
GNPs-3\%, and $\mathrm{TiO}_{2}-12 \%$ & $78.09,50 \mathrm{~Hz}, 150{ }^{\circ} \mathrm{C}$ & $9.18,50 \mathrm{~Hz}, 150{ }^{\circ} \mathrm{C}$ \\
\hline
\end{tabular}

EM waves using $\mathrm{TiO}_{2}$ NPs [16]. The intercalated layers of MMT with its high aspect ratio along with GNPs i.e. flake or disc-like pieces play an effective role in absorbing the EM radiation [64]. Further enhancement of EMI SE can also be possible with increased loading of nanofillers into the PVDF matrix, but the mechanical stability of the resulting nanocomposite gets deteriorated on a higher concentration of fillers [8]. For the maximum loading of GNPs and $\mathrm{TiO}_{2}$ NPs i.e., for PVDF/GNPs/TiO 2 nanocomposite film with GNPs-3\% and $\mathrm{TiO}_{2}-12 \%$, the EMI SE value slightly decreases as compared with the lower loadings of GNPs and $\mathrm{TiO}_{2}$ NPs. Table 3 depicts the literature survey for EMI SE of various PNCs [2, 5, 16, 23, 49, 64-66]. Therefore, with minimal incorporation of GNPs, MMT and $\mathrm{TiO}_{2}$ NPs, a significant enhancement in EMI SE was observed which signifies that this nanocomposite material can be a potential candidate for EMI shielding application. 


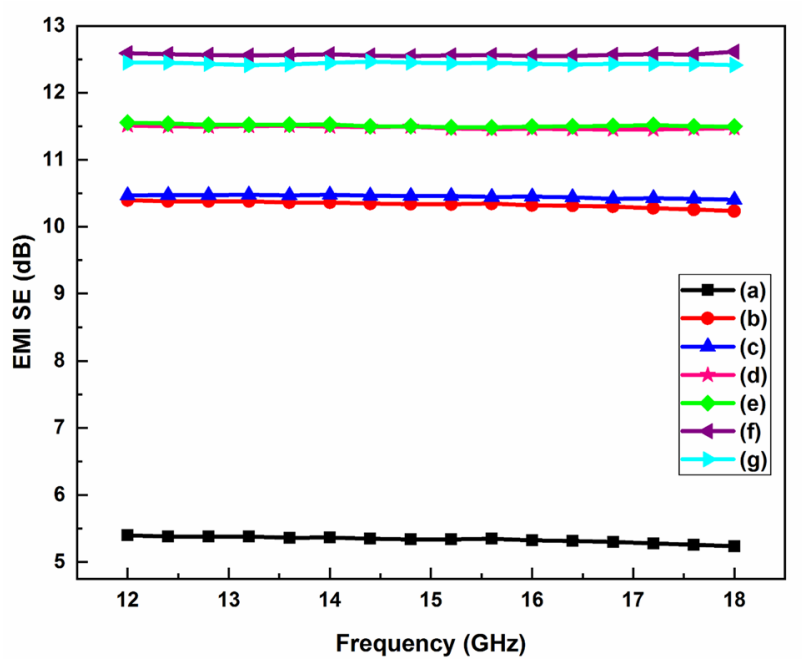

Fig. 8 EMI SE in the Ku band region for (a) pristine PVDF, (b) $\mathrm{PVDF} / \mathrm{GNPs} / \mathrm{MMT} / \mathrm{TiO}_{2}$ nanocomposite film with GNPs- $0.5 \%$, MMT-5\% and $\mathrm{TiO}_{2}-9.5 \%$, (c) GNPs- $1 \%$, MMT- $4 \%$ and $\mathrm{TiO}_{2}-10 \%$, (d) GNPs- $1.5 \%$, MMT-3\% and $\mathrm{TiO}_{2}-10.5 \%$, (e) GNPs-2\%, MMT-2\% and $\mathrm{TiO}_{2}-11 \%$, (f) GNPs-2.5\%, MMT-1\% and $\mathrm{TiO}_{2}-11.5 \%$ and $(\mathrm{g})$ GNPs-3\% and $\mathrm{TiO}_{2}-12 \%$

\section{Conclusions}

In the present work, PVDF/GNPs/MMT/TiO ${ }_{2}$ nanocomposite films were successfully prepared using the solution casting method. The properties of prepared nanocomposites were investigated using different analysis techniques such as FTIR, XRD, FESEM and dielectric analysis. The FTIR results infer good interaction between the nanofillers and the polymer matrix. FESEM micrographs demonstrate the homogenous dispersion of the nanofillers in the polymer matrix. The good interaction between the nanofillers and the polymer matrix with the homogeneous dispersion of the nanofillers within the polymer matrix led to the enhancement of the dielectric properties of the nanocomposites. The maximum dielectric constant of PVDF film was found to be 47.11 at $50 \mathrm{~Hz}, 150{ }^{\circ} \mathrm{C}$ and that of the PVDF/GNPs/MMT/TiO ${ }_{2}$ nanocomposite film was observed to be 210.92 at $50 \mathrm{~Hz}, 150{ }^{\circ} \mathrm{C}$ for GNPs$2 \%$, MMT $-2 \%$ and $\mathrm{TiO}_{2}-11 \%$ loading. This value of the dielectric constant of nanocomposite film was 4.5 times greater than that of pristine PVDF film. On the other hand, the maximum dielectric loss tangent value was determined to be 10.4 at $50 \mathrm{~Hz}, 150{ }^{\circ} \mathrm{C}$ for the same compositions of the PVDF/GNPs/MMT/TiO ${ }_{2}$ nanocomposite film which can be due to the increased conductivity of the nanocomposites. The maximum EMI SE of $12.6 \mathrm{~dB}$ was obtained in the $\mathrm{Ku}$-band region for PVDF/GNPs/MMT/TiO 2 nanocomposites with GNPs- $2.5 \%$, MMT- $1 \%$ and $\mathrm{TiO}_{2}-11.5 \%$ loading. The enhanced EMI SE values in the Ku-band frequency region can be attributed to the higher aspect ratio of nanofillers and the formation of conducting interconnected network between the nanofillers and the PVDF matrix. The obtained results suggest the potential of the prepared nanocomposites as an EMI shielding material.
Table 3 Summary of EMI SE values of various PNCs

\begin{tabular}{lllccc}
\hline Nanofillers & Loading (wt\%) & Polymer matrix & $\begin{array}{l}\text { Maximum } \\
\text { EMI SE } \\
(\mathrm{dB})\end{array}$ & Frequency $(\mathrm{GHz})$ & References \\
\hline $\mathrm{h}-\mathrm{BNNP}$ & 25 & PVDF & 11.21 & $8-12$ & {$[2]$} \\
$\mathrm{NiO}+\mathrm{WO}_{3}$ & $20+5$ & PVC & 12.05 & $8-12$ & {$[5]$} \\
$\mathrm{TiO}_{2}$ & 25 & PVA/PSSA & 13 & $8-12$ & {$[16]$} \\
$\mathrm{MWCNTs}+\mathrm{BaTiO}_{3}$ & $3.7+7.5$ & PVDF-HFP-LiBF & 81 & $8-12$ & {$[23]$} \\
$\mathrm{Graphene}$ & 15 & PVDF & 47 & $8-12$ & {$[49]$} \\
$\mathrm{MMT}$ & 20 & PPy & -32.63 & $8.6-12.4$ & {$[64]$} \\
$\mathrm{rGO}$ & 2 & Epoxy & 38 & $0.5-4$ & {$[65]$} \\
$\mathrm{GNPs}$ & 15 & PLA & 15.5 & $8-12$ & {$[66]$} \\
$\mathrm{GNPs}+\mathrm{MMT}+\mathrm{TiO}_{2}$ & $2.5+1+11.5$ & PVDF & 12.6 & $8-12$ & This work \\
\hline
\end{tabular}

GNPs graphene nanoplatelets, $r G O$ reduced graphene oxide, $P V D F$ polyvinylidene fluoride, $P L A$ polylactic acid, $M M T$ montmorillonite, $P P y$ polypyrrole, $h$ - $B N N P$ hexagonal boron nitride nanoparticles, $\mathrm{TiO}_{2}$ titanium dioxide, $P V A$ polyvinyl alcohol, PSSA polystyrene sulfonic acid, MWCNTs multiwalled carbon nanotubes, $\mathrm{BaTiO}_{3}$ barium titanate, $\mathrm{PVDF}$ - $\mathrm{HFP}$ poly(vinylidene fluoride-co-hexafluoropropylene), $\mathrm{LiBF}_{4}$ lithium tetrafluoroborate, $\mathrm{NiO}$ nickel oxide, $\mathrm{WO}_{3}$ tungsten oxide, $\mathrm{PVC}$ polyvinyl chloride

Acknowledgement The authors Dr. M. Basheer Ahamed and A. Harish Kumar are very grateful to the Department of Science and TechnologyScience and Engineering Research Board (DST-SERB), Government 
of India, for providing the financial support to this research work under the sanctioned Project Number EMR/2016/006705.

\section{References}

1. S. Sankaran, K. Deshmukh, M.B. Ahamed, S.K.K. Pasha, Recent advances in electromagnetic interference shielding properties of metal and carbon filler reinforced flexible polymer composites: a review. Composites A 114, 49-71 (2018)

2. S. Sankaran, K. Deshmukh, M.B. Ahamed, K.K. Sadasivuni, M. Faisal, S.K.K. Pasha, Electrical and Electromagnetic Interference (EMI) shielding properties of hexagonal boron nitride nanoparticles reinforced polyvinylidene fluoride nanocomposite films. Polym. Plast. Technol. Mater. 58, 1191-1209 (2019)

3. A. Muzaffar, M.B. Ahamed, K. Deshmukh, M. Faisal, Electromagnetic interference shielding properties of polyvinylchloride (PVC), barium titanate $\left(\mathrm{BaTiO}_{3}\right)$ and nickel oxide $(\mathrm{NiO})$ based nanocomposites. Polym. Test. 77, 105925 (2019)

4. A. Muzaffar, M.B. Ahamed, K. Deshmukh, M. Faisal, S.K.K. Pasha, Enhanced electromagnetic absorption in $\mathrm{NiO}$ and $\mathrm{BaTiO}_{3}$ based polyvinylidenefluoride nanocomposites. Mater. Lett. 218 , 217-220 (2018)

5. A. Muzaffar, M.B. Ahamed, K. Deshmukh, S.K.K. Pasha, Dielectric properties and electromagnetic interference shielding studies of nickel oxide and tungsten oxide reinforced polyvinylchloride nanocomposites. Polym. Plast. Technol. Mater. 59, 1667-1678 (2020)

6. P. Rani, M.B. Ahamed, K. Deshmukh, Dielectric and electromagnetic interference shielding properties of carbon black nanoparticles reinforced PVA/PEG blend nanocomposite films. Mater. Res. Express 7, 064008 (2020)

7. J. Joseph, K. Deshmukh, K. Chidambaram, M. Faisal, E. Selvarajan, K.K. Sadasivuni, M.B. Ahamed, S.K.K. Pasha, Dielectric and electromagnetic interference shielding properties of germanium dioxide nanoparticle reinforced poly(vinyl chloride) and poly(methylmethacrylate) blend nanocomposites. J. Mater. Sci. Mater. Electron. 29, 20172-20188 (2018)

8. P. Rani, M.B. Ahamed, K. Deshmukh, Electromagnetic interference shielding properties of graphene quantum-dots reinforced poly(vinyl alcohol)/polypyrrole blend nanocomposites. J. Appl. Polym. Sci. 137(45), 49392 (2020)

9. P. Rani, M.B. Ahamed, K. Deshmukh, Significantly enhanced electromagnetic interference shielding effectiveness of monmorillonitrile nanoclay and copper oxide nanoparticles based polyvinylchloride nanocomposites. Polym. Test. 91, 106744 (2020)

10. L. Reddy, K. Deshmukh, T. Kovarik, D. Reiger, N.A. Nambiraj, R. Lakhmipathy, S.K.K. Pasha, Enhanced dielectric properties of green synthesized nickel sulphide nanoparticles integrated polyvinyl alcohol nanocomposites. Mater. Res. Express 7, 064007 (2020)

11. K. Deshmukh, S.K.K. Pasha, Room temperature ammonia sensing based on graphene oxide integrated flexible polyvinylidene fluoride/cerium oxide nanocomposite films. Polym. Plast. Technol. Mater. 59, 1429-1446 (2020)

12. L. Reddy, K. Deshmukh, T. Kovarik, N.A. Nambiraj, S.K.K. Pasha, Green chemistry mediated synthesis of cadmium sulphide/ polyvinylalcohol nanocomposites: assessment of microstructural, thermal and dielectric properties. Polym. Compos. 41, 2054-2067 (2020)

13. M.K. Mohanapriya, K. Deshmukh, K.K. Sadasivuni, G.J. Thangamani, K. Chidambaram, M.B. Ahamed, S.K.K. Pasha, Enhanced quality factor of polyvinyl formal (PVF) based nanocomposites filled with zinc oxide and carbon black nanoparticles for wireless sensing applications. Mater. Today Proc. 9, 199-216 (2019)

14. P.L. Reddy, K. Deshmukh, K. Chidambaram, M.B. Ahamed, K.K. Sadasivuni, D. Ponnamma, R. Lakshmipathy, D. Dayananda, S.K.K. Pasha, Effect of polyethyleneglycol (PEG) on structural, thermal and photoluminescence properties of $\mathrm{CdO}$ nanoparticles for optoelectronic applications. Mater. Today Proc. 9, 175-183 (2019)

15. P.L. Reddy, K. Deshmukh, K. Chidambaram, M.M. Nazir Ali, K.K. Sadasivuni, Y. Ravi Kumar, R. Lakshmipathy, S.K.K. Pasha, Dielectric properties of polyvinyl alcohol (PVA) nanocomposites filled with green synthesized zinc sulphide $(\mathrm{ZnS})$ nanoparticles. J. Mater. Sci. Mater. Electron. 30, 4676-4687 (2019)

16. M.K. Mohanapriya, K. Deshmukh, J. Kadlec, K.K. Sadasivuni, M. Faisal, N.A. Nambiraj, S.K.K. Pasha, Dynamic mechanical analysis and broadband electromagnetic interference shielding characteristics of poly (vinyl alcohol)-poly (4-styrenesulfonic acid)-titanium dioxide nanoparticles based tertiary nanocomposites. Polym. Plast. Technol. Mater. 59, 847-863 (2019)

17. Y.R. Kumar, K. Deshmukh, K.K. Sadasivuni, S.K.K. Pasha, Graphene quantum dots based materials for sensing, bioimaging and energy storage applications: a review. RSC Adv. 10, 23861-23898 (2020)

18. R.S. Dongre, K.K. Sadasivuni, K. Deshmukh, A. Mehta, S. Basu, J.S. Meshram, M.A.A. Al-Maadeed, A. Karim, Natural polymer based composite membranes for water purification: a review. Polym. Plast. Technol. Mater. 58, 1295-1310 (2019)

19. K.K. Sadasivuni, J.J. Cabibihan, K. Deshmukh, S. Gautham, M.K. Abubasha, J.P. Gogoi, I. Klemenoks, G. Sakale, B.S. Sekhar, P.S.R. Sreekanth, K.V. Rao, M. Knite, A review on porous polymer composite materials for multifunctional electronic applications. Polym. Plast. Technol. Mater. 58, 12531294 (2019)

20. H. Aghamohammadi, R. Eslami-Farsani, A. Tcharkhtchi, The effect of multi-walled carbon nanotubes on the mechanical behavior of basalt fibers metal laminates: an experimental study. Int. J. Adhes. Adhes. 98, 102538 (2020)

21. P. Rani, M.B. Ahamed, K. Deshmukh, Dielectric and electromagnetic interference shielding properties of zeolite $13 \mathrm{X}$ and carbon black nanoparticles based PVDF nanocomposites. J. Appl. Polym. Sci. (2020). https://doi.org/10.1002/app.50107

22. P. Rani, M.B. Ahamed, K. Deshmukh, Structural, dielectric and EMI shielding properties of polyvinyl alcohol/chitosan blend nanocomposites integrated with graphite oxide and nickel oxide nanofillers. J. Mater. Sci. Mater. Electron. (2020). https://doi. org/10.1007/s10854-020-04855-w

23. M.K. Vyas, A. Chandra, Synergistic effect of conducting and insulating fillers in polymer nanocomposite films for attenuation of X-band. J. Mater. Sci. 54, 1304-1325 (2019)

24. S.K. Sharma, V. Gupta, R.P. Tandon, V.K. Sachdev, Synergic effect of graphene and MWCNT fillers on electromagnetic shielding properties of grapheme-MWCNT/ABS nanocomposites. RSC Adv. 6, 18257-18265 (2016)

25. S.M. Pawde, K. Deshmukh, Studies on surface properties of polymeric coated paper material. J. Appl. Polym. Sci. 101, 4167-4171 (2006)

26. S.M. Pawde, K. Deshmukh, Surface characterization of air plasma treated polyvinylidene fluoride and polymethylmethacrylate films. Polym. Eng. Sci. 49, 808-811 (2009)

27. S.M. Pawde, K. Deshmukh, Investigation of the structural, thermal, mechanical and optical properties of poly(methylmethacrylate) and poly (vinylidenefluoride) blends. J. Appl. Polym. Sci. 114, 2169-2179 (2009)

28. K. Deshmukh, G.M. Joshi, Novel nanocomposites of graphene oxide reinforced poly (3, 
4-ethylenedioxythiophene)-block-poly(ethyleneglycol) and polyvinylidene fluoride for embedded capacitor. RSC Adv. 4, 37954-37963 (2014)

29. D. Satapathy, K. Deshmukh, M.B. Ahamed, K.K. Sadasivuni, D. Ponnamma, S.K.K. Pasha, M.A.A. AlMaadeed, J. Ahmad, High-quality factor poly (vinylidenefluoride) based novel nanocomposites filled with graphene nanoplatelets and vanadium pentoxide for high-Q capacitor applications. Adv. Mater. Lett. 8, 288-294 (2017)

30. K. Deshmukh, M.B. Ahamed, R.R. Deshmukh, S.K.K. Pasha, K.K. Sadasivuni, D. Ponnamma, M.A.A. AlMaadeed, Striking multiple synergies in novel three-phase fluoropolymer nanocomposites by combining titanium dioxide and graphene oxide as hybrid fillers. J. Mater. Sci. Mater. Electron. 28, 559-575 (2016)

31. H. Aghamohammadi, R. Eslami-Farsani, M. Torabian, N. Amousa, Recent advances in one-pot functionalization of graphene using electrochemical exfoliation of graphite: a review. Synth. Met. 269, 116549 (2020)

32. K. Deshmukh, S.M. Khatake, G.M. Joshi, Surface properties of graphene oxide reinforced polyvinylchloride nanocomposites. J. Polym. Res. 20, 286 (2013)

33. W.K. Chee, H.N. Lim, Z. Zainal, N.M. Huang, I. Harrison, Y. Andou, Flexible graphene-based supercapacitors: a review. J. Phys. Chem. C 120, 4153-4172 (2016)

34. H.J. Choi, S.M. Jung, J.M. Seo, D.W. Chang, L. Dai, J.B. Baek, Graphene for energy conversion and storage in fuel cells and supercapacitors. Nano Energy 1, 534-551 (2012)

35. F. Bonaccorso, Z. Sun, T. Hasan, A.C. Ferrari, Graphene photonics and optoelectronics. Nat. Photonics 4, 611-622 (2010)

36. G. Wang, X. Shen, J. Yao, J. Park, Graphene nanosheets for enhanced lithium storage in lithium ion batteries. Carbon $\mathbf{4 7}$, 2049-2053 (2009)

37. P. Cataldi, A. Athanassiou, I.S. Bayer, Graphene nanoplateletsbased advanced materials and recent progress in sustainable applications. Appl. Sci. 8, 1438 (2018)

38. I. Mutlay, L.B. Tudoran, Percolation behavior of electrically conductive graphene nanoplatelets/polymer nanocomposites: theory and experiment. Fuller. Nanotubes Carbon Nanostruct. 22, 413433 (2014)

39. R. Keshavarz, H. Aghamohammadi, R. Eslami-Farsani, The effect of graphene nanoplatelets on the flexural properties of fiber metal laminates under marine environmental condition. Int. J. Adhes. Adhes. 103, 102709 (2020)

40. E. Kazemi-Khasragh, F. Bahari-Sambran, C. Platzer, R. EslamiFarsani, The synergistic effect of graphene nanoplatelets-montmorillonite hybrid system on the tribological behaviour of epoxybased nanocomposites. Tribol. Int. 151, 106472 (2020)

41. Y. Li, S.C. Tjong, Electrical properties of binary PVDF/clay and ternary graphite-doped PVDF/clay nanocomposites. Curr. Nanosci. 8, 732-738 (2012)

42. Q.Y. Peng, P.H. Cong, X.J. Liu, T.X. Liu, S. Huang, T.S. Li, The preparation of PVDF/clay nanocomposites and the investigation of their tribological properties. Wear 266, 713-720 (2009)

43. W. Yu, Z. Zhao, W. Zheng, Y. Song, B. Li, B. Long, Q. Jiang, Structural characteristics of poly (vinylidene fluoride)/clay nanocomposites. Mater. Lett. 62, 747-750 (2008)

44. J. Ahmad, K. Deshmukh, M.B. Hägg, Influence of $\mathrm{TiO}_{2}$ on the chemical, mechanical, and gas separation properties of polyvinyl alcohol-titanium dioxide ( $\left.\mathrm{PVA}-\mathrm{TiO}_{2}\right)$ nanocomposite membranes. Int. J. Polym. Anal. Charact. 18, 287-296 (2013)

45. K. Deshmukh, J. Ahmad, G.M. Joshi, M.B. Ahamed, M.B. Hägg, Stability and electrokinetic properties of aqueous $\mathrm{TiO}_{2}$ nanoparticle dispersion in polyallylamine and polyvinylalchol blend systems. Int. J. Polym. Res. 21, 393 (2014)
46. S. Ishaq, F. Kanwal, S. Atiq, M. Moussa, U. Azhar, D. Losic, Dielectric properties of graphene/titania/polyvinylidene fluoride $\left(\mathrm{G} / \mathrm{TiO}_{2} / \mathrm{PVDF}\right)$ nanocomposites. Materials 13, 205 (2020)

47. D.Y. Wang, Y.P. Song, J.S. Wang, X.G. Ge, Y.Z. Wang, A.A. Stec, T.R. Hull, Double In situ approach for the preparation of polymer nanocomposite with multi-functionality. Nanoscale Res. Lett. 4, 303-306 (2009)

48. G. Polizos, E. Tuncer, I. Sauers, K.L. More, Physical properties of epoxy resin/titanium dioxide nanocomposites. J. Polym. Eng. Sci 51, 87-93 (2011)

49. K. Sabira, M.P. Jayakrishnan, P. Saheeda, S. Jayalekshmi, On the absorption dominated EMI shielding effects in free standing and flexible films of poly(vinylidene fluoride)/graphene nanocomposite. Eur. Polym. J. 99, 437-444 (2018)

50. M. Hamidinejad, B. Zhao, A. Zandieh, N. Moghimian, T. Filleter, C.B. Park, Enhanced electrical and electromagnetic interference shielding properties of polymer-graphene nanoplatelet composites fabricated via supercritical-fluid treatment and physical foaming. ACS Appl. Mater. Interfaces 10, 30752-30761 (2018)

51. J.M. Thomassin, C. Jérôme, T. Pardoen, C. Bailly, I. Huynen, C. Detrembleur, Polymer/carbon based composites as electromagnetic interference (EMI) shielding materials. Mater. Sci. Eng. R 74, 211-232 (2013)

52. A. Salimi, A.A. Yousefi, FTIR studies of $\beta$-phase crystal formation in stretched PVDF films. Polym. Test. 22, 699-704 (2003)

53. A.S. Lanceros-Mendez, J.F. Mano, V.H. Schmidt, FTIR and DSC studies of mechanically deformed $\beta$-PVDF films. J. Macromol. Sci. 527, 517-527 (2001)

54. P. Taylor, Z. Danková, A. Mockov, S. Dolinská, Z. Dankova, Desalination and water treatment influence of ultrasound irradiation on cadmium cations adsorption by montmorillonite. Desalin. Water Treat. 52, 5462-5469 (2014)

55. C. Zhang, L. Zhong, D. Wang, F. Zhang, G. Zhang, Anti-ultraviolet and anti-static modification of polyethylene terephthalate fabrics with graphene nanoplatelets by a high-temperature and highpressure inlaying method. Text. Res. J. 89, 1488-1499 (2018)

56. Y. Wang, J. Yang, K. Du, Q. Yin, Q. Yin, Polypyrrole/graphene/ polyaniline ternary nanocomposite with high thermoelectric power factor. ACS Appl. Mater. Interfaces 9, 20124-20131 (2017)

57. N. Ahmad, S.T. Hussain, B. Muhammad, N. Ali, S.M. Abbas, Y. Khan, Effect of manganese promotion on Al-pillared montmorillonite supported cobalt nanoparticles for Fischer-Tropsch synthesis. Bull. Korean Chem. Soc. 34, 3005-3012 (2013)

58. C.R. Silva, R.M. Lago, H.S. Veloso, P.S.O. Patrisio, Use of amphiphilic composites based on clay/carbon nanofibers as fillers in UHMWPE. J. Braz. Chem. Soc. 29, 278-284 (2018)

59. D. Ponnamma, H. Parangusan, K. Deshmukh, P. Kar, A. Muzaffar, S.K.K. Pasha, M.B. Ahamed, M.A.A. AlMaadeed, Green synthesized materials for sensor, actuator, energy storage and energy generation: a review. Polym. Plast. Technol. Mater. 59, $1-62(2020)$

60. K. Deshmukh, M.B. Ahamed, K.K. Sadasivuni, D. Ponnamma, R.R. Deshmukh, S.K.K. Pasha, M.A.A. AlMaadeed, K. Chidambaram, Graphene oxide reinforced polyvinyl alcohol/polyethylene glycol blend composites as high-performance dielectric material. J. Polym. Res. 23, 159 (2016)

61. K. Deshmukh, S. Sankaran, M.B. Ahamed, K.K. Sadasivuni, S.K.K. Pasha, D. Ponnamma, P.S.R. Sreekanth, K. Chidambaram, Dielectric Spectroscopy. In: Spectroscopic Methods for Nanomaterial Characterization: Micro and Nano Technologies (Elsevier, Amsterdam, 2017), pp. 237-299

62. K. Deshmukh, M.B. Ahamed, S. Sankaran, S.K.K. Pasha, K.K. Sadasivuni, D. Ponnamma, M.A.A. AlMaadeed, Studies on the mechanical, morphological and electrical properties of highly dispersible graphene oxide reinforced polypyrrole and polyvinyl 
alcohol blend composites. Mater. Today Proc. 5, 8744-8752 (2018)

63. K. Deshmukh, S. Sankaran, M.B. Ahamed, S.K.K. Pasha, K.K. Sadasivuni, D. Ponnamma, M.A.A. AlMaadeed, K. Chidambaram, Studies on the electrical properties of graphene oxidereinforced poly (4-styrene sulfonic acid) and polyvinyl alcohol blend composites. Int. J. Nanosci. 17, 1760005-1760013 (2017)

64. J. Jin, J. Song, S. Deng, G. Li, Synthesis and microwave absorbing characteristics of flake-like polypyrrole filled composites in X-band. Polym. Compos. 37, 532-538 (2014)

65. N. Yousefi, X. Sun, X. Lin, X. Shen, J. Jia, B. Zhang, B. Tang, M. Chan, J.K. Kim, Highly aligned graphene/polymer nanocomposites with excellent dielectric properties for high-performance electromagnetic interference shielding. Adv. Mater. 26, 5480$5487(2014)$

66. S. Kashi, R.K. Gupta, T. Baum, N. Kao, S.N. Bhattacharya, Morphology, electromagnetic properties and electromagnetic interference shielding performance of poly lactide/graphene nanoplatelet nanocomposites. Mater. Des. 95, 119-126 (2016)

Publisher's Note Springer Nature remains neutral with regard to jurisdictional claims in published maps and institutional affiliations. 